\title{
Los Mendigos del Portal del Señor en "El Señor Presidente" de Miguel Angel Asturias
}

Dra. Jenny Margoth Zelaya Matamoros*

\begin{abstract}
A pesar de que el libro "El Señor Presidente" del guatemalteco Miguel Ángel Asturias fue publicado en 1946, o sea hace más de sesenta y cinco años, la similitud con la realidad actual de muchos pueblos latinoamericanos es más que una coincidencia. La novela se enfoca en la entrada a la ciudad: El Portal del Señor, que no es otro que el lugar predilecto de los mendigos para reunirse y dormir. La muerte de uno de los hombres de confianza del Señor Presidente pone en marcha la trama de la novela.
\end{abstract}

Es así que este trabajo tiene la finalidad de brindar al lector una reflexión acerca de los mendigos del Portal del Señor y su rol en la novela, en la cual Asturias muestra la lucha tenaz que se desarrolla entre el pueblo guatemalteco y el dictador. Aunque Asturias selecciona trabajar con los mendigos como fieles representantes del pueblo, no son los únicos que reciben maltratos y muerte. Son un grupo más que marginado, son un grupo que vive con miedo.

Palabras Clave: <mendigos>, <Señor Presidente>, <muerte>, $<$ miedo $>$.

A lo largo de las páginas ingeniosas de El Señor Presidente (1946) de Miguel Ángel Asturias, el lector se encuentra con una serie de situaciones llenas de violencia, desesperación, ironía, e intereses personales y políticos que hacen vibrar a toda una nación. En la novela "se esboza la caricatura de un dictador típico de Latinoamérica y de un régimen sangriento y viciado hasta lo máximo de

\footnotetext{
* Docente, Departamento de Letras y Lenguas, Universidad Pedagógica Nacional Francisco Morazán.
} 
descomposición moral y social" (Arango: p. 117). Aunque la novela no específica el lugar donde se llevan a cabo los hechos, el marco histórico de la misma se sitúa en Guatemala durante la dictadura de veintidós años (1898-1920) de Manuel Estrada Cabrera. Durante este período, los habitantes de Guatemala se encontraban sometidos bajo un sistema de terror que parecía no tener fin. "A booklet published in 1915, which could well have cost its author's life, tells the following tale of woe, as translated by the author:

\section{The people of Guatemala are defenseless and unarmed and under}

these conditions an armed protest against tyranny is impossible; laws prohibit the importation and sale of any kinds of weapons and arms. The trade in saltpeter and powder is a government monopoly.

Besides this, the tyranny of Guatemala, like all tyrannies, only knows how to maintain itself in power by the use of terror, which weakens the will, and by the subjugation to the armed forces unto eternity; for this reason terror is spread by mysterious murders, clandestine persecutions and arbitrary imprisonments; executions that have no semblance of justice. ..." (Rosenthal, $p$. 165)

De forma similar a lo que expresa este boletín, Asturias recrea en su novela el terror vivido por el pueblo guatemalteco en ese tiempo histórico. Al igual que ellos, la mayoría de los personajes de la novela son víctimas que gritan en silencio la crueldad de un gobierno basado en la violencia y en la tiranía. Asturias hace que cada uno de sus personajes transmita al lector una idea clara y palpable del sufrimiento humano bajo tales condiciones.

Asturias va hilando entre línea y línea el daño irreparable que el gobierno hace al pueblo y también presenta una delimitación clara de las clases sociales y de la violencia que existe entre ellas, siendo la más afectada la clase desprotegida. Desde el comienzo de la novela, Asturias introduce a los personajes más miserables y solos: los mendigos del Portal del Señor, quienes forman un grupo de seres lanzados al olvido y sin más esperanza que encontrar en el basurero algo para saciar su hambre. Un mendigo es por definición, una "persona que habitualmente pide limosna" (Diccionario Enciclopédico 
Ilustrado, p. 794), es decir que solicita a otros un favor usualmente acompañado de la auto-humillación. Los mendigos configuran una parte oscura de cualquier país y son la credencial de la pobreza en su más clara expresión. Se ven obligados a vivir en el patio trasero y para muchos ciudadanos, se vuelven hasta invisibles.

Son los mendigos los elegidos, por Asturias, para formar el esqueleto principal de la novela y son ellos la causa del hecho más relevante de la misma. No es difícil para el lector discernir la actitud de sobrevivencia que los mendigos llevan a cuestas. Tampoco es difícil distinguirles como personajes individuales y al mismo tiempo reconocer su colectividad representada a través de su concepción como títeres de un sistema nefasto; al que le es sumamente fácil e indiferente tomar la vida de cualquier pordiosero con tal de llevar a cabo sus objetivos. Este ensayo tiene como propósito principal mostrar la importancia del rol de los mendigos en la novela y evidenciar que son ellos el comienzo y el fin de la misma.

El primer capítulo de la novela lleva como título "El Portal del Señor", lo cual da la idea de la entrada al paraíso o a la salvación eterna con una hueste de ángeles celestiales dando la bienvenida a los recién llegados. Irónicamente, este capítulo está dedicado a describir el tipo de relación y situación que existen entre los hijos menos afortunados de la patria, de una patria sin nombre:

En las gradas del portal se les veía, vueltos a la pared, contar el dinero, morder las monedas de níquel para saber si eran falsas, hablar a solas, pasar revistas a las provisiones de boca y de guerra, que de guerra andaban en la calle armados de piedras y escapularios, y engullirse a escondidas cachos de pan en seco. (El Señor, p. 10)

Esta introducción detallada de las actitudes de los mendigos con ellos mismos y con los demás hace que el lector se dé cuenta de la cruda realidad que acompaña a este grupo social que no es más que el producto desechado del régimen autoritario del Señor Presidente.

Al volverse a la pared para contar el dinero y comerse el pan a escondidas, los mendigos demuestran su condición temerosa, mezquina y su lucha por la sobrevivencia. No existe entre ellos ningún lazo de solidaridad y mucho menos de amistad. "Se comportan 
como verdaderas alimañas, escupiéndose, mordiéndose en arrebatos de rabia bestial” (Navarro, p. 56). Es así que “[n]unca se supo que se socorrieran entre ellos; avaro de sus desperdicios, como todo mendigo preferirían darlos a los perros antes que a sus compañeros de infortunio" (El Señor, p. 10). Cada uno de los mendigos mira en el otro a un enemigo en potencia porque es lo que les impone la dictadura; a desconfiar del vecino y a vivir con temor.

A lo largo de la novela, el lector puede darse cuenta que esta forma de vida que los mendigos llevan no es tan diferente a la de los demás personajes. Todos buscan sobrevivir sin importar lo que pueda pasar. No hay un capítulo en la novela en el que los personajes desarrollen lazos de amistad entre ellos, ni siquiera entre los más afortunados como Miguel Cara de Ángel y los militares más allegados al Señor Presidente.

Al deslizar su mirada por el primer capítulo, el lector esboza en su mente una imagen vívida y real de los infortunados del Portal de El Señor, quienes, contradictoriamente, esperan la luz del sol que les trae, quizás un poco de esperanza con la llegada de un nuevo día. Sin embargo, no todos pueden disfrutar de esa luz, ya que algunos no la puedan ver, pues son ciegos. El lector empieza a entrar en ese mundo ignorado y olvidado que sólo pertenece a los mendigos. Éstos dejan de ser una colectividad y se convierten en personajes individuales y particulares. Sin embargo, la única forma de saber quiénes son es identificándolos por su sobrenombre o sus limitaciones físicas, lo cual los hace más universales, ya que pueden ocupar un lugar en cualquier país del mundo que se encuentre bajo la misma situación. Ellos son "seres extraños, ex vidas: El Pelele (un trastornado de corpulencia viva) hijo de un gallero y de una pobre madre (con fijación de ella a través de su nombre genérico), "El Viuda" de perfil mulato, "El Patahueca", con su característico e inconcluso "Viva Francia" mencionado en cualquier acto de su vida y "El Mosco" que se rebela ante los tratos de la policía" (Castelpoggi 45). Además de ellos, la novela también incluye a una "sordomuda" que está esperando un bebé y a una "ciega" que se mece "en sueños colgada de un clavo cubierta de moscas, como la carne en las carnicerías" (El Señor, p. 12). 
Estos sobrenombres son utilizados por Asturias con una finalidad más profunda que el simple hecho de hacer sus limitaciones más visibles u obvias. Pelele, por ejemplo, significa una persona que puede ser manejada al antojo de otra; algo así como un títere y ese es, exactamente, el rol que este mendigo tiene en la novela. Irónicamente, el Pelele reacciona un día, por cuenta propia, y mata a un ser humano cuando éste quiere hacerse pasar por "títiretero". Por otro lado, el sobrenombre de Patahueca, presupone a una persona que tiene una pierna de palo, lo que pone en claro su limitación física. Además de eso, su usual muletilla ¡Viva Francia!, traspone el supuesto del deseo de una revolución como la otrora acontecida en Francia en 1789. Otro de los mendigos, es el Mosco, cuyo sobrenombre denota el macho de la mosca, un insecto muy desagradable. De allí, que el apodo es bastante despectivo. Todos estos personajes son marginados por la sociedad y Asturias le da un poco más de ironía a su novela al concederle a un "idiota" la batuta de protagonizar el evento que pone en marcha el motor de los eventos que se desarrollan en la misma. Es así que las acciones que se desarrollan se mueven paulatinamente de los mendigos a los estratos más altos de la sociedad.

El primer mendigo que surge en la novela es Patahueca con la vocalización de su frase favorita “Viva Francia!” (El Señor, p. 10). Inmediatamente, el Pelele es presentado al lector como un objeto de diversión para los demás:

Con los ojos lejos de las caras monstruosas de sus compañeros, sin ver nada, sin oír nada, sin sentir nada, fatigado por el llanto, se quedaba dormido; pero al dormirse, carretilla de todas las noches, la voz de Patahueca le despertaba:

- iMadre!...

El Pelele abría los ojos de repente, como el que sueña que rueda en el vacío; dilataba las pupilas más y más, ... Pero al dormirse, al no más dormirse, la voz de otra prenda con boca le despertaba:

- ¡Madre! ... .

Era la voz de la Viuda, mulato degenerado... (El Señor, p. 11).

Y así poco a poco el lector va conociendo a los mendigos de El Portal del Señor. Asturias muestra cómo la cruel deshumanización de los mendigos y su sufrimiento les convierten en seres insensibles al 
dolor ajeno. El Pelele, por ejemplo, se desespera y actúa furiosamente cuando oye la palabra "Madre". Los demás se burlan de él sin ni siquiera sospechar el dolor inmenso que "el idiota" lleva por dentro. La madre de Pelele no sólo fue la que le dio el ser sino que también fue la única que le dio ternura, comprensión y lo aceptó tal como era:

En el pecho materno se alivió. Las entrañas de la que le había dado el ser absorbieron como papel secante el dolor de sus heridas. (El Señor, p. 25-6)

La relación entre Pelele y su madre era constantemente mancillada por su padre borracho:

Historia de nunca acabar la de sus penas: hembra de aquel cualquiera y mártir del crío que nació ... en su agonía se juntaron la cabeza desproporcionada de su hijo-una cabezota redonda y con dos coronillas como la luna-, las caras huesudas de los enfermos del hospital y los gestos de miedo, de asco, de hipo, de ansia, de vómito del gallero borracho. (El Señor, p. 25)

Es este "idiota" fatigado de no dormir por muchas noches, ansiando estar con su madre y sirviendo de objeto de burla para los demás, el utilizado por Asturias para desequilibrar el mundo del Señor Presidente al quitarle la vida a alguien que no sólo disturbó su sueño sino que también lo llevaría a la muerte paulatinamente:

Sólo el Pelele dormía a pierna suelta por una vez, roncando. El bulto se detuvo- la risa le entorchaba la cara-, acercóse al idiota de puntapié y, en son de broma, le gritó:

- Madre!

No dijo más. Arrancado del suelo y por el grito, el Pelele se le fue encima y, sin darle tiempo a que hiciera uso de sus armas, le enterró los dedos en los ojos, le hizo pedazos la nariz a dentelladas y le golpeó las partes con las rodillas hasta dejarlo inerte" (El Señor, $p$. 13).

Asturias explícitamente aclara al lector que el Pelele duerme como un niño, después de pasar tantas noches de desvelo, cuando "un bulto" se acerca como una pesadilla para inquietarle. Y el "bulto" disfruta haciéndolo. El Pelele, que probablemente ya está cansado 
de ser hostigado por sus compañeros, reacciona violentamente ante aquel abuso del que es objeto, sin saber que al cometer ese crimen estaría firmando su sentencia de muerte. Es hasta más tarde en la novela que el lector se entera que la víctima de el Pelele es el Coronel José Parrales Sonriente, alias "el hombre de la mulita", "el más poderoso de los agentes de la dictadura, y este episodio inicial pone en funcionamiento la máquina infernal del dictador" (Anderson, p. 53), ya que desde ese momento el Señor Presidente no sólo convertiría las calles de la nación en campos de despliegue militar, sino que también haría que sus espías políticos consiguiesen información hasta en los lechos amorosos del prostíbulo. "Confuso por el asesinato que acaba de cometer, el idiota Pelele... se refugia en un basurero. Allí entre la inmundicia, se queda dormido. De pronto es atacado por una bandada de zopilotes hambrientos. Malherido, aterrorizado, el idiota cae semiinconsciente por un despeñadero" (Navarro, p. 53-4), lo cual hace que se fracture una pierna y entre en un estado de delirio y alucinación.

La situación frente a la cual el Pelele se encuentra ahora no es muy diferente a la que usualmente vive en el Portal del Señor. Si bien es cierto que está rodeado por la basura mal oliente y putrefacta, al menos no será perturbado en su delirio con la palabra "Madre", aunque ella está siempre presente en su delirio. De esta forma, Asturias muestra cómo el Pelele halla un poco de paz entre la basura y los zopilotes y no entre sus "camaradas de lucha". Después de todo a los otros mendigos no les interesa el bienestar de los demás en su grupo. Cada quien lucha por salvar su propio "pellejo" sin importar los demás y así lo demuestran cuando son llevados a prisión para ser interrogados acerca de la muerte trágica y sádica de tan "útil elemento" en el gobierno de terror del Señor Presidente: el coronel Sonriente.

El segundo capítulo claramente anuncia la muerte de uno de los mendigos del famoso Portal del Señor al llevar por título "La Muerte del Mosco". El Mosco es un ciego que perdió los ojos y las piernas en unas cuantas borracheras y es un miembro asiduo del grupo que cada noche asiste al Portal del Señor. Cuando lo llevan capturado a la prisión, lo introducen en una "bartolina estrechísima y oscura" (El Señor, p.15) llamada “Las Tres Marías”. De inmediato, él se da 
cuenta de que el miedo es un prisionero más en la celda donde están los demás mendigos cuando escucha que:

Sus compañeros lagrimeaban como animales con moquillo, atormentados por la oscuridad, que sentían que no se les iba a despegar más de los ojos; por el miedo- estaban allí, donde tantos y tantos habían padecido hambre y sed hasta la muerte- y porque les infundía pavor que los fueran a hacer jabón de noche, como a los chuchos, o a degollarlos para darle de comer a la policía" (El señor, p. 15).

Es allí, en las celdas de la prisión, donde los mendigos parecen tener algo en común que todos comparten: el miedo. Temen por sus vidas y a la oscuridad, aunque estén acostumbrados a ella porque saben que tarde o temprano les acompañará para siempre en sus tumbas. Los mendigos son llevados a la prisión por órdenes del Auditor de Guerra con la finalidad de ser interrogados. Como es usual en un país donde la tiranía y el poder político se encuentran a la vuelta de la esquina, los mendigos son interrogados uno por uno, probablemente a media noche, cuando nadie ve lo que está pasando pero todos lo saben. El Auditor de Guerra, no estando satisfecho con la respuesta proporcionada por cada uno de los mendigos al principio, decide amenazarles para obtener la tan ansiada verdad:

- iMe van a decir la verdad!- gritó, desnudando los ojos de basilisco tras los anteojos de miope, después de dar un puñetazo sobre la mesa que servía de escritorio. Uno por uno repitieron aquellos que el autor del asesinato del Portal era el Pelele, refiriendo con voz de ánimas en pena los detalles del crimen que ellos mismos habian visto con sus propios ojos". ( $p$ 17).

Cada uno de los mendigos dice lo que vio y en su razonamiento creen que el Auditor busca la verdad de lo que sucedió la noche anterior. Sin embargo, el Auditor de Guerra, respaldado por el Señor Presidente, tiene otros planes en mente y los pone en marcha tan pronto como la situación se lo permite. Él quiere que se culpe al general Eusebio Canales y al Licenciado Abel Carvajal, por razones políticas, de la muerte del Coronel Sonriente. Para poder obtener las declaraciones que necesita para mandar a encarcelar a los dos supuestos culpables, el Auditor ordena que se torture a los mendigos 
hasta que declaren una mentira que ellos saben les asegurará la vida y la libertad. Cuando el Auditor dice los nombres de los supuestos asesinos:

Sobrevino un gran silencio helado; luego, luego una queja, otra queja más luego y por último un sí . . . Al soltar la cuerda, el Viuda cayó de bruces sin conciencia. Carbón mojado por la lluvia parecían sus mejillas de mulato empapadas en sudor y llanto. Interrogados a continuación sus compañeros, que temblaban como los perros que en la calle mueren envenenados por la policía, todos afirmaron las palabras del auditor menos el Mosco" ( El Señor, p. 18).

Al sostener la verdad ante el Auditor, el Mosco pretende, quizás, que los demás se unan a él y digan la verdad. Sin embargo, cada mendigo quiere seguir viviendo, aunque sea miserablemente. Al Auditor no le conviene dejar libre a una persona que asegura que un idiota fue el verdadero causante de la muerte de un Coronel y por eso los policías le arrancan la vida a latigazos al hombre que a pesar de tener miedo y "a pesar de la tortura que causa su muerte... nunca renuncia a la verdad” (Urza, 83).

La policía sacó a botar el cuerpo del Mosco en una carreta de basura que se alejó con dirección al cementerio. Empezaban a cantar los gallos. Los mendigos en libertad volvieron a las calles. (El Señor, $p$. 19).

Al igual que el Pelele, el Mosco también encuentra su lugar con la basura y se integra a ella de forma natural como si en realidad fueran de la misma clase y hechos del mismo material. Este segundo capítulo cierra con el comienzo de un nuevo día y los mendigos vuelven a su lugar, sin ni siquiera percatarse que uno de ellos lleva el camino al cementerio junto con la basura porque eso es lo que son para este sistema cruel y deshumanizante, que cada vez los margina más y los aleja no sólo de la sociedad sino también de ellos mismos.

Más adelante en la novela, el lector se enfrenta con la verdad de que varias personas están sufriendo como consecuencia del acto fúrico de un idiota. Sin saber su destino, el Pelele logra salir del basurero con la ayuda del leñador y la mano derecha del Presidente, Miguel Cara de Ángel. Él trata de retornar al único lugar que conoce 
como hogar en vez de seguir las instrucciones dadas por el leñador de que vaya al hospital y busque ayuda para su pierna quebrada. Sin saberlo, el Pelele se dirige hacia su muerte, quien lo aguarda en las manos de Lucio Vásquez:

El idiota se quejaba quedito y recio como un perro herido. Un alarido desgarró la noche. Vásquez, a quien Pelele vio acercarse con la pistola en la mano, lo arrastraba de la pierna quebrada hacía las gradas que caían a la esquina del Palacio Arzobispal. Rodas asistía a la escena, sin movimiento, con el resuello espeso empapado en sudor. Al primer disparo el Pelele se desplomó por la gradería de piedra. Otro disparo puso fin a la obra (El Señor, p. 54).

Finalmente, la vida de la persona que causó una conmoción general en la nación había sido tomada. Muertes como la de Pelele y el Mosco quedan impunes ante tanta corrupción.

La trama de la novela está basada en el acto inconsciente de Pelele, quien ya descansa en paz junto a su madre y al Mosco. De acuerdo con John Walker:

"choosing the idiot as a representative of the innocent, the a-political, who suffer the abuses of a totalitarian regime, Asturias underlines the point by showing how dictatorship corrupts a people and destroys its values to the extent even compassion for one's companions in distress ceases to exist"(63).

La muerte de uno de los personajes más relevantes de la novela pone de manifiesto las políticas del Señor Presidente, quien no desaprovecha la oportunidad para manipular los acontecimientos y usarlos a su conveniencia. La muerte de Pelele no es sentida por ningún otro personaje en la novela. Pasa más bien desapercibida al igual que varios de los acontecimientos en la dictadura. Al final de la novela, el lector descubre que el Portal del Señor ya no existe. Al mandar a derribarlo, el Señor Presidente no sólo quiere borrar el recuerdo terrible de la muerte del Coronel Sonriente, sino que también desea fervientemente quitarles el lugar de reunión y abrigo a los mendigos. Sin embargo, con seguridad ellos encontrarán otro lugar donde acobijarse del frío durante las noches oscuras. De acuerdo con Castelpoggi, los mendigos "representan algo así como una de 
las imágenes del reflejo de ese azogue inmóvil que es la dictadura. Ambiente y personas a la vez, en protagonización concreta de los hechos marco e interior de los mismos" (43). Con los mendigos del Portal, Asturias crea un ambiente real y palpable de la historia de un pueblo. Cada uno de los mendigos tiene su historia y su importancia en la novela. Ellos hacen que día a día se recuerde que la realidad no se construye con espejismos que disfrazan las acciones que derrumban la sociedad. A diferencia de otros personajes como Cara de Ángel, los mendigos forman un grupo al que no se puede olvidar y mucho menos borrar de la faz de la tierra. En muchos países hay miles de portales del señor y cuando se derrumba uno, diez más surgen albergando muchos Peleles, Moscos y Patahuecas. 


\section{Bibliografía}

- Anderson Imbert, Enrique. "Análisis de El Señor Presidente". Revista Iberoamericana. Pittsburgh, PA: 35: 53-57. 1969.

- Arango, Manuel Antonio. Aspectos Sociales en Ocho Escritores Hispanos. Bogotá, Colombia: Ediciones Tercer Mundo. 1981.

- Asturias, Miguel Ángel. El Señor Presidente. Buenos Aires, Argentina: Editorial Losada, S.A. Tercera Edición. 1959.

- Castelpoggi, Atilio Jorge. Miguel Ángel Asturias. Buenos, Aires, Argentina: Editorial "La Mandrágora”. 1961.

- Diccionario Enciclopédico Ilustrado. Bogotá, Colombia: Zamora Editora Ltda. 2009.

- Navarro, Carlos. "La Hipotiposis del Miedo en El Señor Presidente". Revista Iberoamericana. Pittsburgh, PA: 32:51-61. 1966.

- Rosenthal, Mario. Guatemala. New York: Twayne Publishers Inc. 1962.

- Urza, Carmelo. "Metáfora y Deshumanización en El Señor Presidente". Explicación de Textos Literarios. Sacramento, CA: 14 (1): 79-83. 1985-1986.

- Walker, John. "The Role of the Idiot in Asturias' El Señor Presidente". Romance Notes.Chapel Hill, NC: 12: 62-67. 1970. 